\title{
Comparative Study on the Vitamin C Contents of the Food Legume Seeds
}

\author{
Michie MORIYAmA ${ }^{1}$ and Kazuko OBA ${ }^{2}$ \\ ${ }^{1}$ Department of Home Economics, Aichi Gakusen University, 28 Kamikawanari, Hegoshi-cho, Okazaki, \\ Aichi 444-8520, Japan \\ ${ }^{2}$ Department of Food and Nutritional Sciences, College of Bioscience and Biotechnology, Chubu University, \\ 1200 Matsumoto-cho Kasugai, 487-8501, Japan
}

(Received March 5, 2007)

\begin{abstract}
Summary We found that dehydrated legume seeds (6 genera, 19 species and cultivated varieties) contained considerable amounts of vitamin C (VC). The average value of total VC content per $100 \mathrm{~g}$ of dry weight in dehydrated seeds varied from $0.24 \mathrm{mg}$ (kidney beans) to $4.14 \mathrm{mg}$ (green peas). Yard beans showed highest values among all legumes examined here in the both dehydrated and rehydrated forms ( 3.19 and $10.8 \mathrm{mg}$, respectively). By soaking for $16 \mathrm{~h}$ in the dark at $20^{\circ} \mathrm{C}$, total $\mathrm{VC}$ contents of black grams and mung beans increased to 3.1- and 4.5-fold, respectively. However, three varieties of green peas (Hakuryu, Kurumeyutaka, and Nankaimidori) significantly lost their $\mathrm{VC}$ during the same soaking treatment. Total VC content of a rehydrated and cooked mung beans was higher than that of a dehydrated form. Appreciable amounts of total VC were detected in the immature seeds of six different genera such as yard beans, kidney beans, broad beans, green peas, soybeans and peanuts. Except for mung beans, $70-100 \%$ of VC in dehydrated seeds of adzuki beans, broad beans, green peas, black soybeans, and soybeans was lost by boiling. Total VC and L-ascorbic acid in mung beans, green peas, broad beans, black soybeans, and adzuki beans remained even after boiling, suggesting that it is possible to obtain $\mathrm{VC}$ from the cooked forms of these legume seeds.
\end{abstract}

Key Words vitamin C, legume seed, L-ascorbic acid, imbibition, cooking

The superiority of legume seeds as a general nutrient source and the physiological functions of proteins, fat and non-nutritional elements of legume seeds have been attracting both researchers' and consumers' attention (1).

Since mature legume seeds can be stored long-term after dehydration, legume seeds are generally distributed in the market in dehydrated forms. Though it is well known that the ascorbic acid (AsA) concentration significantly increases in the embryonic axes and cotyledons during the germination of rehydrated peas (Pisum sativum L.) in the dark (2), dehydrated legume seeds have long been referred to as food stuffs virtually without vitamin C (VC). "The Fifth Table of Standard Japanese Food Composition" states that dehydrated legume seeds contain only a trace amount of $\mathrm{VC}$, i.e. less than $1.0 \mathrm{mg} \mathrm{VC} / 100 \mathrm{~g}$ tissue, which is the minimum value for listing criteria (3), while immature legume seeds and their sprouts are indicated to contain high levels of $\mathrm{VC}(8-40 \mathrm{mg} / 100 \mathrm{~g}$ fr. wt. of tissue). However, we recently revealed that immature legume seeds and their sprouts contain the same amount of $\mathrm{VC}$ as fresh vegetables at the time of harvest $(4,5)$. The fact encouraged us to analyze the $\mathrm{VC}$ contents of various legume seeds using the HPLC-post column derivative method, which is one of the most sensitive procedures

E-mail: moriyama@gakusen.ac.jp to determine both AsA and dehydroascorbic acid (DHA) simultaneously (6-8). This is a different way of detecting VC content from that used for "The Fifth Table of Standard Japanese Food Composition."

In the present study, we will show that dehydrated legume seeds familiar in the Japanese market contain distinct amounts of $\mathrm{VC}$, which increase with few exceptions when the dehydrated legume seeds are soaked in water. We also found that some legume seeds retain a small amount of VC even after boiling and cooking.

\section{MATERIALS AND METHODS}

1. Immature and dehydrated mature legume seeds. Immature and dehydrated mature legume seeds were obtained directly from a breeder and the Japan Agricultural Cooperative (JA).

Legumes listed in Table 1 were used in this study. We didn't know what species were measured in each genus of bean for The Fifth Table of Standard Japanese Food Composition, so we investigated three or four species in each genus except peanuts. Black grams and mung beans were used after storage for $4 \mathrm{y}$ at $2^{\circ} \mathrm{C}$. The other legume seeds were used within a maximum of 5-mo storage at $2^{\circ} \mathrm{C}$ after harvest.

2. Preparation of rehydrated and cooked legume seeds. To rehydrate legume seeds, dry seeds were soaked in 5 volumes of water for $16 \mathrm{~h}$ in the dark at $20^{\circ} \mathrm{C}$. Tissue weight was measured before and after 
soaking; the ratio of rehydrated weight/dry weight is shown (Table 1). To prepare boiled legume seeds, dry legume seeds were rehydrated in water for $2 \mathrm{~h}$ at $20^{\circ} \mathrm{C}$ and then boiled. The boiled legume seeds were immediately washed once with cool water and then boiled in 5-10 volumes of water for $1 \mathrm{~h}$. These were called "cooked legume seeds" in this study.

3. Analytical procedures. Dehydrated legume seeds were milled for $2 \mathrm{~min}$ with a universal mill (Tokyo Unicom Co., Ltd.). Rehydrated legume seeds, immature legume seeds and cooked legume seeds were completely homogenized with a mortar and pestle. The milled and homogenized legume seeds $(10 \mathrm{~g})$ were suspended in $50 \mathrm{~mL}$ of pre-chilled $6.0 \%$ metaphosphoric acid solution, and homogenized with a homo blender (Matsushita Electric Industrial Co. Ltd.) for $3 \mathrm{~min}$ at $0^{\circ} \mathrm{C}$. The homogenate was made up to $100 \mathrm{~mL}$ with the same buffer and centrifuged at 38,000 $\times g$ for $10 \mathrm{~min}$. Supernatants were filtrated through no. 2 filter paper (Toyo Roshi Kaisha, Ltd.) and then further filtrated with a PTFE membrane $(0.20 \mu \mathrm{m}$ pore size, Toyo Roshi Kaisha, Ltd.).

The ascorbic acid and the DHA contents of the legume seeds were analyzed using the HPLC-post column derivative method described in a previous paper by modifying the method of Yasui et al. $(6,7)$. Filtered extracts were applied onto a Shim-Pack SCR-102H column $(8 \times 300 \mathrm{~mm})$, which had been equilibrated with $2.0 \mathrm{~mm}$ perchloric acid (Wako Pure Chemical Industries, Ltd.), and eluted with the same solvent at $40^{\circ} \mathrm{C}$. The flow rate was $1.0 \mathrm{~mL} / \mathrm{min}$. The eluate containing AsA or DHA was mixed with $50 \mathrm{~mm}$ tetrahydrofolic acid and $100 \mathrm{~mm}$ sodium hydroxide at $20^{\circ} \mathrm{C}$ (flow rate $=0.5 \mathrm{~mL} / \mathrm{min}$ ), and absorption at $300 \mathrm{~nm}$ of the reaction mixture was monitored. Amounts of AsA and DHA in the legume seeds were calculated based on the elution profiles by using known amounts of standard AsA and DHA (Wako Pure Chemical Industries, Ltd.). Concentrations of AsA and DHA of dehydrated, rehydrated and cooked legume seeds were shown in $100 \mathrm{~g}$ dry weight. We did an official examination of total VC content of every species in the same genus for dehydrated and rehydrated legume seeds by Tukey-Kramer and Scheffe's $F$ test.

\section{RESULTS AND DISCUSSION}

1. Increase in the tissue weight of dehydrated legume seeds after soaking in water

The tissue weights of various legume seeds before and after soaking in water are shown in Table 1. The dehydrated legume seeds swelled considerably after soaking in water. The weight ratio of rehydrated to dehydrated seeds was high $(>2.0)$ in green peas (average 2.35) and soybeans (average 2.22). We suggested percent of water included in the seeds has the effect of maintaining the VC content. The ratio for peanuts was the lowest (1.58) probably because of their high fat content $(47.5 \mathrm{mg}$ fat/ $100 \mathrm{~g}$ dry wt.) (3). The average ratios for yard beans, kidney beans and broad beans were between 1.85 and 1.96. Legumes such as yard beans, kidney beans, and broad beans have a very hard seed coat, which probably explains the lower absorption of water by those legumes during the soaking treatment.

\section{Contents of VC in dehydrated legume seeds}

The contents of total VC, AsA and DHA per $100 \mathrm{~g}$ dry weight, were determined with the HPLC-post column derivative method for 19 dehydrated legume seeds (Table 1).

1) Yard beans. In three legumes classified as yard beans, the highest content of total VC per $100 \mathrm{~g}$ dry weight was found in mung beans $(6.50 \mathrm{mg})$, and the lowest in black grams $(0.45 \mathrm{mg})$. The content of total VC per $100 \mathrm{~g}$ dry weight in adzuki beans was $2.61 \mathrm{mg}$. Burkholder and Mcveigh (9) compared the content of AsA in garden peas, mung beans and several strains of soybeans, and reported that the reduced and total AsA content of dry matter was higher for mung beans than peas and soybeans. In addition Wai et al. (10) also detected the reduced AsA and DHA in mung beans before soaking. Mung beans are using by traditional Chinese medicine, so we guess that the Chinese are well acquainted with those excellent components from their routine experiences.

2) Kidney beans. Among four varieties of kidney beans, the content of total VC per $100 \mathrm{~g}$ dry weight was high in Kintoki beans $(0.84 \mathrm{mg})$ and low in Tora beans $(0.10 \mathrm{mg})$. However, varieties Murasakihana and uzura beans did not contain any appreciable amount of VC. Benibana ingen, which is another name for Murasakihana beans have a trace of VC content according to The Fifth Table of Standard Japanese Food Composition, and that result is as same as in our experiment. The content of total VC per $100 \mathrm{~g}$ dry weight was very low in an average of four varieties of kidney beans, but we might say that the genus does not lack seed VC heritably.

3) Broad beans. Among three varieties of broad beans, variety Nintokuissun showed the lowest VC content per $100 \mathrm{~g}$ dry weight $(0.21 \mathrm{mg})$. VC content was high in variety Sanukinagasaya wase $(2.01 \mathrm{mg})$ and low in wase broad bean $(1.65 \mathrm{mg})$. The Fifth Table of Standard Japanese Food Composition shows no or a trace amount of VC content in broad beans but in 1992 Arrigoni et al. reported that dry Vicia fava L. contain small amount of DHA and before desiccation the legume had a large amount of AsA (11). We report a small amount of AsA and DHA content in dry broad beans, so that we suggest this different result was caused by the difference in VC assays.

4) Green peas. The highest content of total VC per $100 \mathrm{~g}$ dry weight in four cultivated varieties of green peas was found in variety Nankaimidori $(7.40 \mathrm{mg})$, which was followed by varieties Kurumeyutaka (5.59 $\mathrm{mg}$ ), Hakuryu (3.23 mg) and Usui (0.32 mg). These results are in good agreement with the report by Pallanca and Smirnoff (2) that a small but distinct amount of AsA is detected in dry pea seeds.

5) Soybeans. The total VC content per $100 \mathrm{~g}$ dry weight in four varieties of soybeans lies the following order: Tsurunoko (3.50 mg), Tamahomare (2.48 mg), black soybeans $(1.95 \mathrm{mg})$ and Ohsode $(0.72 \mathrm{mg})$. Every 
Vitamin C Contents of the Food Legume Seeds

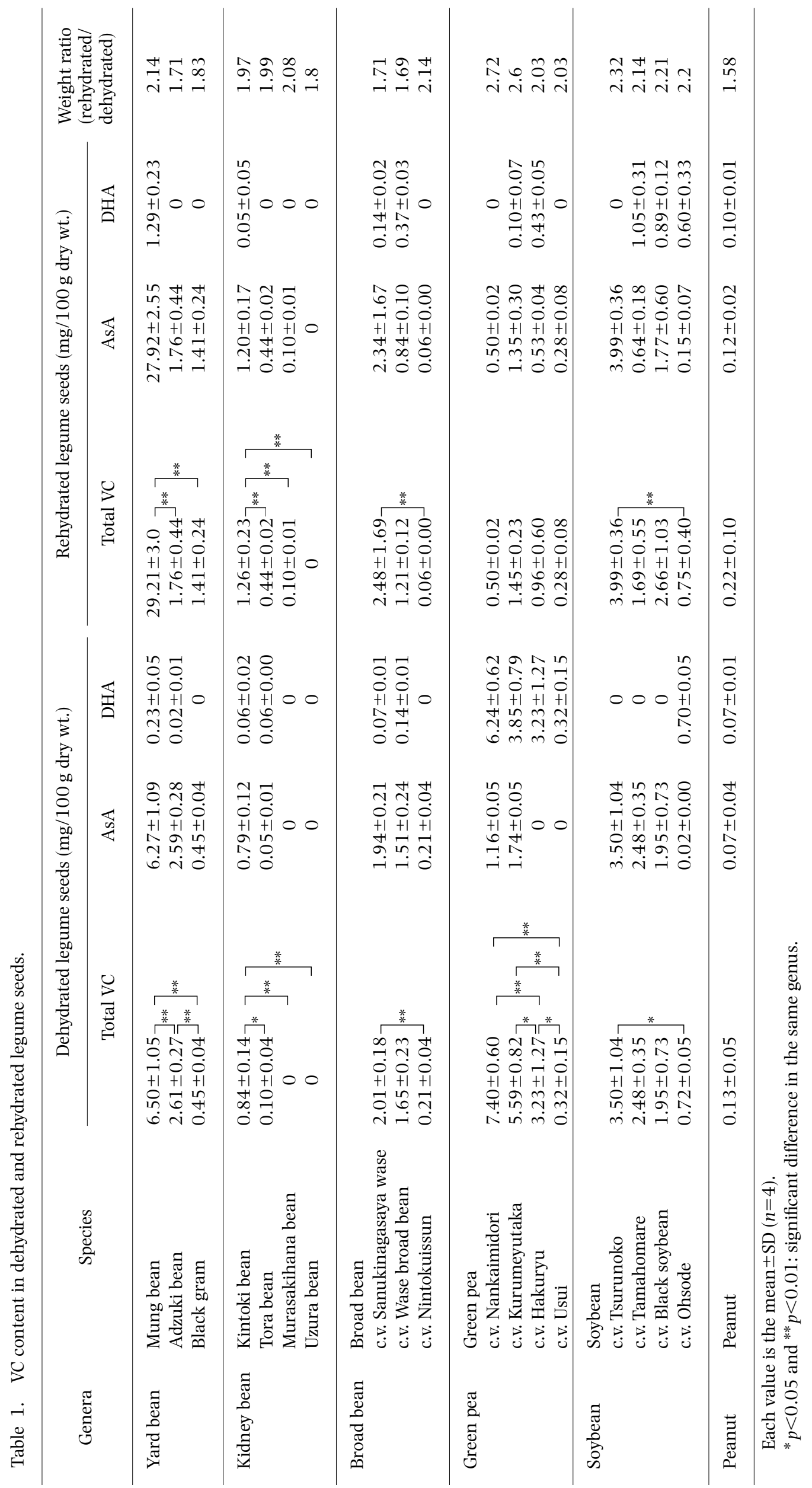


species in the soybean genus showed a higher weight ratio of rehydrated/dehydrated legume seeds, which means all legume seeds of the soybean genus included a small amount of water while total VC content was in the form of AsA content except in Ohsode.

6) Peanuts. The content of total VC per $100 \mathrm{~g}$ dry weight in peanuts was very low $(0.13 \mathrm{mg})$, although the amounts were enough to be detected by the HPLCpost column derivative method used in this study.

The present results indicated that at least ten different species of dehydrated legume seeds in four different genera, which are familiar in Japan, contain more than $1.0 \mathrm{mg} \mathrm{VC} / 100 \mathrm{~g}$ of dry weight, although "The Fifth Table of Standard Japanese Food Composition" describes dehydrated legume seeds as containing virtually no VC, or if any, less than listing criteria $(1.0 \mathrm{mg} \mathrm{VC} /$ $100 \mathrm{~g}$ dry wt.) (3). Average contents of total VC per $100 \mathrm{~g}$ dry weight in dehydrated seeds of five different legumes, i.e. yard beans, kidney beans, broad beans, green peas, and soybeans, ranged from 0.24 to $4.14 \mathrm{mg}$. Dehydrated seeds of the green peas and yard beans showed higher amounts of total VC (4.14 and $3.19 \mathrm{mg}$, respectively) than those of other legumes. In the method of VC assay used for "The Fifth Table of Standard Japanese Food Composition," AsA was oxidized at once to produce osazone and then analyzed using HPLC. Oba et al. compared the method used here and that used for "The Fourth Table of Standard Japanese Food Composition" when analyzing total VC contents of fresh vegetables (6), and reported that total VC content by the procedure used here resulted in only $80 \%$ of that by that used for "The Fourth Table of Standard Japanese Food Composition." The difference could result from the fact that we excluded 2,3 diketo-guronic acid from our VC assay.

3. Changes in VC content of legume seeds after soaking in water

Legume seeds are generally distributed in the market as dehydrated ones, so they must be soaked overnight (8-16 h) in cold water before cooking. Table 1 shows the contents of total VC, AsA and DHA per $100 \mathrm{~g}$ dry weight of various legume seeds after soaking for $16 \mathrm{~h}$ in water in the dark.

1) Yard beans. Among three varieties of yard beans, the highest total VC content per $100 \mathrm{~g}$ dry weight of rehydrated seeds was found in mung beans $(29.21 \mathrm{mg})$, which is more than 16 times higher than those of adzuki beans $(1.76 \mathrm{mg}, \quad p<0.01)$ and black grams (1.41 mg, $p<0.01)$. Oba elucidated the mechanism of AsA increase in mung beans during germination (12). The activity of L-galactono- $\gamma$-lactone dehydrogenase (EC 1.3.2.3, GLDH) was scarcely detected in dry seeds and increased rapidly after the inbibition. Interestingly, the content of total VC per $100 \mathrm{~g}$ dry weight in rehydrated seeds of black grams and mung beans, which are widely used as "bean sprouts" in the Japanese kitchen, was significantly higher $(>3$-fold, $p<0.01)$ than those in dehydrated seeds. On the other hand, adzuki beans lost $33 \%$ of the total VC when rehydrated (see Table 1).

2) Kidney beans. Among four varieties of kidney beans, the highest content of total VC per $100 \mathrm{~g}$ dry weight in rehydrated seeds was found in Kintoki beans (1.26 mg), followed by varieties Tora beans $(0.44 \mathrm{mg})$ and Murasakihana beans $(0.10 \mathrm{mg})$. VC was not detected in the rehydrated uzura beans. The contents of total VC in the rehydrated seeds of Kintoki beans and Tora beans after soaking were 1.5-fold and 4.4-fold higher than those of their dehydrated seeds. VC became detectable in the rehydrated seeds of variety Murasakihana beans, though it was not detected in uzura beans even in their rehydrated form.

3) Broad beans. The total VC contents per $100 \mathrm{~g}$ dry weight in the rehydrated seeds of three varieties of broad beans were in the following order; Sanukinagasaya wase $(2.48 \mathrm{mg})$, wase broad beans $(1.21 \mathrm{mg})$ and Nintokuissun $(0.06 \mathrm{mg})$. The content of total VC in the seeds of the variety Sanukinagasaya wase increased after soaking, but those of varieties Nintokuissun and wase broad beans decreased during the treatment.

4) Green peas. The total VC content of rehydrated seeds per $100 \mathrm{~g}$ dry weight in four cultivated varieties of green peas were in the following order: Kurumeyutaka $(1.45 \mathrm{mg}) \geqq$ Hakuryu $(0.96 \mathrm{mg}) \geqq$ Nankaimidori $(0.50$ $\mathrm{mg})>$ Usui $(0.28 \mathrm{mg})$. The total content of the seeds reduced significantly after soaking except for the variety Usui. Mapson and Moustafa (13) demonstrated the reduction of DHA as a result of hydrogen transfer from glutathione; reduced glutathione and ascorbic acid act as respiratory carriers in the enzyme system which transfers hydrogen to molecular oxygen from germinating pea seeds. In 1950, Yamaguchi and Joslyn reported glutathione was absent in dry pea seeds (14).

5) Soybeans. The total VC content in rehydrated seeds per $100 \mathrm{~g}$ dry weight in three cultivated varieties of soybeans examined were more than $1.0 \mathrm{mg}$ as follows: Tsurunoko (3.99 mg), black soybeans $(2.66 \mathrm{mg})$, and Tamahomare $(1.69 \mathrm{mg})$. Rehydrated seeds of the variety Ohsode showed low VC content $(0.75 \mathrm{mg})$. The total VC content in dehydrated seeds of varieties Tsurunoko, Tamahomare, and black soybeans were also higher than $1.0 \mathrm{mg}$, except for that of the variety Ohsode. The total VC content of legume seeds per $100 \mathrm{~g}$ dry weight in soybeans increased after soaking, except for the variety Tamahomare. The average content of total VC in the rehydrated seeds in four soybeans examined was higher than those in all other legumes but yard beans.

6) Peanuts. The content of total VC of rehydrated seeds of peanuts per $100 \mathrm{~g}$ dry weight increased slightly during soaking (from 0.13 to $0.22 \mathrm{mg}$ ).

In the present paper, we demonstrated that the total VC content in rehydrated legume seeds of black gram and mung beans dramatically increased more than 3fold that of the dehydrated seeds, suggesting that AsA was synthesized de novo during the rehydration of seeds in water. Morinaga reported that the total VC content of black grams was not changed during the rehydration process, but that the addition of L-galactono- $\gamma$-lactone (L-GAL) as a physiological precursor of AsA to the rehydration buffer significantly increased the VC content 
Table 2. VC content in fresh immature legume seeds of immediately after harvest.

\begin{tabular}{|c|c|c|c|c|}
\hline \multirow{2}{*}{ Genera } & \multirow{2}{*}{ Species } & Total VC & AsA & DHA \\
\hline & & \multicolumn{3}{|c|}{ (mg/100 g fr. wt.) } \\
\hline Yard bean & Mung bean & $21.4 \pm 1.27$ & $11.0 \pm 0.97$ & $10.4 \pm 0.37$ \\
\hline Kidney bean & Kintoki bean & $22.3 \pm 2.71$ & $8.9 \pm 1.63$ & $13.5 \pm 1.24$ \\
\hline Broad bean & Broad bean & & & \\
\hline & c.v. Nintoku issun & $17.1 \pm 3.99$ & $13.6 \pm 3.67$ & $3.4 \pm 0.31$ \\
\hline Green pea & Green pea & & & \\
\hline & c.v. Hakuryu & $20.4 \pm 0.45$ & $16.1 \pm 0.42$ & $4.3 \pm 0.03$ \\
\hline Soybean & Soybean & & & \\
\hline & c.v. Tsurunoko & $23.4 \pm 0.43$ & $19.3 \pm 0.41$ & $4.1 \pm 0.13$ \\
\hline Peanut & Peanut & $27.8 \pm 0.06$ & $17.9 \pm 0.06$ & $9.9 \pm 0.00$ \\
\hline
\end{tabular}

Each value is the mean $\pm \operatorname{SD}(n=4)$.

Table 3. VC content in cooked legume seeds.

\begin{tabular}{|c|c|c|c|c|}
\hline \multirow{2}{*}{ Genera } & \multirow{2}{*}{ Species } & Total VC & AsA & DHA \\
\hline & & \multicolumn{3}{|c|}{ (mg/100 g dry wt.) } \\
\hline \multirow[t]{2}{*}{ Yard bean } & Mung bean & $9.42 \pm 0.24$ & $8.34 \pm 0.22$ & $1.08 \pm 0.08$ \\
\hline & Adzuki bean & $0.15 \pm 0.03$ & $0.15 \pm 0.03$ & 0 \\
\hline \multirow[t]{2}{*}{ Broad bean } & Broad bean & & & \\
\hline & c.v. Sanukinagasaya wase & $0.55 \pm 0.06$ & $0.55 \pm 0.06$ & 0 \\
\hline \multirow[t]{2}{*}{ Green pea } & Green pea & & & \\
\hline & c.v. Kurumeyutaka & $1.00 \pm 0.15$ & $0.22 \pm 0.17$ & $0.78 \pm 0.70$ \\
\hline \multirow[t]{3}{*}{ Soybean } & Soybean & & & \\
\hline & c.v. black soybean & $0.26 \pm 0.04$ & $0.20 \pm 0.04$ & $0.06 \pm 0.00$ \\
\hline & c.v. Tsurunoko & 0 & 0 & 0 \\
\hline
\end{tabular}

Each value is the mean $\pm \operatorname{SD}(n=4)$.

(15). Although the total VC content of dehydrated legume seeds of green peas was high, the content drastically decreased after soaking for $16 \mathrm{~h}$ at $20^{\circ} \mathrm{C}$. Mapson suggested the existence of glutathione, the chemicaland enzyme-catalyzed reductant of DHA, in dry seeds. Pallanca and Smirnoff reported that AsA content and AsA system in legume seeds were very low in the first $20 \mathrm{~h}$ of imbibition, but in the following $10 \mathrm{~h}$ of imbibition AsA was remarkably accumuled in the seeds, concluding that pea could be a useful system to detect intermediates involved in plant AsA synthesis (2).

4. Vitamin C content in the immature fresh legume seeds

Table 2 shows the VC content of the immature legume seeds per $100 \mathrm{~g}$ fresh weight, which was determined immediately after harvesting. All the immature legume seeds examined contain a considerable amount of total VC (mung beans $21.4 \mathrm{mg}$, kidney bean variety Taisyokintoki $22.3 \mathrm{mg}$, broad bean variety Nintokuissun $17.1 \mathrm{mg}$, green pea variety Hakuryu 20.4 mg, soybean variety Tsurunoko $23.4 \mathrm{mg}$, peanuts $27.8 \mathrm{mg}$ ). It was suggested that these legume seeds lost significant amounts of VC during the dehydration process (see Table 1). Pallanca and Smirnoff reported that the total VC content of pea seedlings significantly increased between 24 and $50 \mathrm{~h}$ after soaking although the AsA is oxidized and destroyed during the desiccation phase of seed development (2).

The present paper demonstrated that immature legume seeds, except for the kidney bean and peanut, contained about $20 \mathrm{mg}$ of total VC per $100 \mathrm{~g}$ fresh weight, and more than $1.0 \mathrm{mg}$ of total VC per $100 \mathrm{~g}$ dry weight remained even after dehydration (Table 1).

5. The effect of cooking on the VC content of various legume seeds

The effect of boiling on the content and composition of $\mathrm{VC}$ in the seeds of 6 legumes, which showed higher $\mathrm{VC}$ content than other legumes in the same genera, i.e. adzuki beans and mung beans from yard beans, variety Sanukinagasaya wase from broad beans, the variety Kurumeyutaka from green peas, and varieties Tsurunoko and black soybeans from soybeans, was examined (Table 3). In the legume seeds analyzed here, boiled seeds of mung beans, which are usually consumed as sprouts in Japan, had a remarkably high content of total VC $(9.42 \mathrm{mg} \mathrm{VC} / 100 \mathrm{~g}$ dry wt.), while other boiled legume seeds had less than $1.00 \mathrm{mg} / 100 \mathrm{~g}$ dry weight of VC. In the Philippines, a popular dish is adzuki and mung beans cooked in sugar water, suggesting that $\mathrm{VC}$ is taken from such dish as a good source of the vitamin in the country. Comparisons of the values 
in Table 1 and Table 3 show that boiled mung beans contain 1.4-times higher amounts of VC than the dehydrated beans do, while other legumes lost 70-100\% VC during the boiling treatment. Though generally people do not expect to take in $\mathrm{VC}$ from dry beans, our results strongly suggest that we can obtain VC from certain cooked beans, e.g., mung beans.

\section{REFERENCES}

1) Carroll KK, Hamilton RMG. 1975. Effect of dietary protein and carbohydrate on plasma cholesterol levels in relation to atherosclerosis. J Food Sci 40: 18-23.

2) Pallanca EJ, Smirnoff N. 1999. Ascorbic acid metabolism in pea seedlings. A comparison of D-glucosone, Lsorbobone, and L-galactono-1, 4-lactone as ascorbate precursors. Plant Physol 120: 453-461.

3) Investigation Committee for Food Composition Study. 2001. The Fifth Table of Standard Japanese Food Composition. Ishiyaku syuppan, Tokyo.

4) Moriyama M, Oba K. 2000. Effect of shell on the change in vitamin $\mathrm{C}$ content of immature legumes during cold storage. J Home Econ Jpn 51: 15-21 (in Japanese).

5) Moriyama M, Oba K. 2004. Vitamin C content and DPPH radical-scavenging of various sprouts and cooked cotyledons of Toumyo. J Home Econ Jpn 55: 153-158 (in Japanese).

6) Oba K, Yamamoto A, Kawai A, Sakata A, Yamazaki M, Niwa M. 2000. Vitamin C content of fresh and prepared vegetables assayed by 2, 4-dinitrophenylhydrazine colorimetric method and HPLC. Vitamins 74: 435-440 (in Japanese).

7) Yasui Y, Hayashi M. 1991. Simultaneous determination of ascorbic acid and dehydroascorbic acid by high performance liquid chromatography. Anal Sci 7: 125-128.

8) Oba K, Yamamoto A, Moriyama M. 2001. Amount of vitamin $\mathrm{C}$ of fresh, frozen and cooked vegetables-Comparison of the values determined by DNP colorimetric method and HPLC—. J Nagoya Women's Univ 47: 67-76 (in Japanese).

9) Burkholder PR, Mcveigh I. 1945. Vitamin content of some mature and germinated legume seeds. Plant Physiol 20: 301-306.

10) Wai KNT, Bishop JC, Mack PB, Cotton RH. 1946. The vitamin content of soybeans and soybean sprouts as function of germintaion time. Plant Physiol 22: 117126.

11) Arrigoni O, DeGara L, Tommasi F, Liso R. 1992. Changes in the ascorbate system during seed development of vicia fava L. Plant Physiol 99: 235-238.

12) Oba K. 1997. Synthesis of L-ascorbic acid in Vigna ungo sprouts. Sequential development of the enzymes involved in the synthesis and metabolism. Plant Physiol 114: s313.

13) Mapson LW, Moustafa EM. 1956. Ascorbic acid and glutathione as respiratory carriers in the respiration of pea seedlings. Biochem J 62: 248-259.

14) Yamaguchi M, Joslyn MA. 1950. Investigation of ascorbic acid dehydrogenase of peas (Pisum sativum) and its distribution in the developing plant. Plant Physiol 26: 757-772.

15) Morinaga Y. 1990. Effects of galactono- $\gamma$-lactone on the formation of L-ascorbic acid in germinating black matpe seeds. J Home Econ Jpn 41: 447-450 (in Japanese). 